\title{
Transcutaneous near-infrared spectroscopy for detection of regional spinal ischemia during intercostal artery ligation: Preliminary experimental results
}

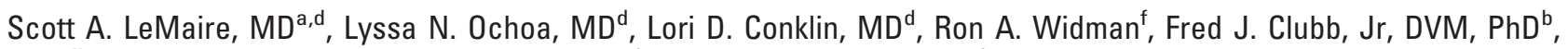
Akif Ündar, PhD ${ }^{\mathrm{c}, \mathrm{e}}$, Zachary C. Schmittling, MD ${ }^{\mathrm{d}}$, Xing Li Wang, MD, PhD ${ }^{\mathrm{d}}$, Charles D. Fraser, Jr, MD ${ }^{\mathrm{a}, \mathrm{e}}$, and Joseph S. Coselli, MD ${ }^{a, d}$

From the Cardiovascular Surgery Service, ${ }^{\text {a }}$ Department of Cardiovascular Pathology, ${ }^{\mathrm{b}}$ and Cullen Cardiovascular Surgical Research Laboratories, ${ }^{\mathbf{c}}$ Texas Heart Institute at St Luke's Episcopal Hospital, Houston, Tex; the Divisions of Cardiothoracic Surgery $^{\mathrm{d}}$ and Congenital Heart Surgery, ${ }^{\mathrm{e}}$ Michael E. DeBakey Department of Surgery, Baylor College of Medicine, Houston, Tex; and the Somanetics Corporation, Troy, Mich. ${ }^{\mathrm{f}}$

Supported by the Michael E. DeBakey Department of Surgery Seed Fund and the Somanetics Corporation, Troy, Mich. R.A.W. is Vice President, Medical Affairs, at Somanetics Corporation, the manufacturer of the device described in this report.

Received for publication March 8, 2006; revisions received April 27, 2006; accepted for publication May 8, 2006.

Address for reprints: Scott A. LeMaire, MD, One Baylor Plaza, BCM 390, Houston, TX 77030 (E-mail: slemaire@bcm. tmc.edu).

J Thorac Cardiovasc Surg 2006;132:1150-5 $0022-5223 / \$ 32.00$

Copyright (๑) 2006 by The American Association for Thoracic Surgery

doi:10.1016/j.jtcvs.2006.05.047
Objective: Real-time information about regional spinal cord ischemia can guide intraoperative management and reduce the risk of paraplegia after thoracic aortic surgery. We hypothesized that near-infrared spectroscopy could provide such information during intercostal and lumbar artery ligation in pigs.

Methods: Transcutaneous near-infrared spectroscopic sensors were placed in the midline over the upper and lower thoracic vertebrae of 4 progressively larger pigs (weight range 21-70 kg). After the entire aorta was exposed, segmental arteries from T6 through L1 were sequentially ligated while regional oxygen saturation was monitored. Decreases in regional oxygen saturation were calculated as percentage changes from baseline. The degrees of ischemia in the upper and lower spinal cord were compared histopathologically.

Results: Baseline regional oxygen saturations were similar in the upper $(68.8 \% \pm$ $9.0 \%)$ and lower $(68.0 \% \pm 11.5 \%, P=.82)$ cord. After ligation, however, regional oxygen saturation levels were significantly lower in the lower cord $(41.3 \% \pm$ $10.1 \%)$ than in the upper cord $(64.8 \% \pm 9.3 \%, P=.037)$. The regional oxygen saturation had decreased by $39.0 \% \pm 11.5 \%$ in the lower cord but only by $6.3 \% \pm$ $7.6 \%$ in the upper cord $(P=.026)$. This difference was confirmed microscopically: upper-cord sections had fewer ischemic neurons $(8.8 \pm 9.4)$ than did lower-cord sections $(21.3 \pm 13.6, P=.002)$.

Conclusion: Intraoperative spinal cord ischemia was detectable with near-infrared spectroscopy in pigs weighing as much as $70 \mathrm{~kg}$. The potential utility of this technique in patients undergoing thoracic aortic surgery warrants investigation.

$\mathrm{T}$ he inability to directly measure spinal cord blood flow and oxygenation intraoperatively is a major obstacle to preventing paraplegia after thoracic aortic surgery. Real-time information about spinal cord ischemia can guide the adjustment of distal aortic perfusion pressure and the reattachment of intercostal arteries. $^{1}$

Current spinal cord monitoring techniques rely on somatosensory-evoked potentials (SSEPs) or motor-evoked potentials (MEPs). Monitoring SSEPs has several disadvantages, including slow response time (caused by delays between the onset of ischemia and the disappearance of potentials) and poor overall sensitivity and specificity. ${ }^{2-4}$ Although MEP monitoring has been successfully used to detect spinal cord ischemia, guide surgical strategy, and prevent postoperative neurologic deficits, it has limitations that have prevented it from being widely adopted. ${ }^{1,5-7}$

Transcutaneous near-infrared spectroscopy (NIRS), which exploits the unique near-infrared absorption profiles of hemoglobin, oxyhemoglobin, and cytochrome aa3, is currently widely used for cerebral oximetry during cardiovascular sur- 


\section{Abbreviations and Acronyms \\ MEP = motor-evoked potential \\ NIRS = near-infrared spectroscopy \\ $\mathrm{SrO}_{2}=$ regional spinal oxygen saturation \\ SSEP = somatosensory-evoked potential \\ TAAA $=$ thoracoabdominal aortic aneurysm}

gery. ${ }^{8-12}$ This technique assesses the oxyhemoglobin fraction within a focal area of underlying tissue by measuring the differential absorption of two wavelengths of nearinfrared light (730 and $810 \mathrm{~nm}$ ) that reflect deoxyhemoglobin and total hemoglobin concentration. The purpose of this pilot study was to assess the feasibility of using NIRS to detect spinal cord ischemia during intercostal artery ligation in the pig.

\section{Materials and Methods}

The protocol for this study was approved by the institutional animal care and use committees of both Baylor College of Medicine and the Texas Heart Institute. The animals received humane care and handling in compliance with the "Principles of Laboratory Animal Care" formulated by the National Society for Medical Research and with the "Guide for the Care and Use of Laboratory Animals" (http://www.nap.edu/catalog/5140.html).

\section{Anesthetic Management}

Four domestic swine (weighing 21, 37, 48, and $70 \mathrm{~kg}$ ) were premedicated with intramuscular atropine sulfate $(0.5 \mathrm{mg} / \mathrm{kg})$, acepromazine maleate $(0.1 \mathrm{mg} / \mathrm{kg})$, and ketamine hydrochloride $(20 \mathrm{mg} / \mathrm{kg})$. Isoflurane $(0.5 \%-3.0 \%)$ was given by mask for induction. Crystalloid fluid was infused throughout the procedure, and boluses of hetastarch were given when needed. Monitors included a pulse oximeter placed on the ear, electrocardiographic leads, and a rectal temperature probe. The animals were orally intubated with a cuffed endotracheal tube through direct laryngoscopy and connected to a volume ventilator that delivered $100 \%$ oxygen at a tidal volume of $10 \mathrm{~mL} / \mathrm{kg}$. General anesthesia was maintained with inhaled isoflurane $(0.5 \%-3.0 \%)$ and pancuronium bromide $(0.1$ $\mathrm{mg} / \mathrm{kg}$ ). A warming blanket was placed underneath the pigs to maintain normothermia. A carotid artery catheter was used for blood pressure monitoring and arterial blood gas sampling.

\section{Operative Procedure}

The dorsal area was shaved and cleaned, and 5100SAF SomaSensors (Somanetics Corporation, Troy, Mich) were placed in the midline over the upper (T6-T7) and lower (T9-T11) thoracic vertebrae. These sensors were connected to an INVOS $5100 \mathrm{Ce}$ rebral Oximeter (Somanetics Corporation). A pediatric spinal drainage catheter was inserted into the subarachnoid space through either a laminectomy or direct puncture between the third and fourth lumbar vertebrae.

A left thoracoabdominal incision was made through the sixth intercostal space. The diaphragm was divided, and the entire thoracoabdominal aorta was exposed. Regional spinal oxygen sat- uration $\left(\mathrm{SrO}_{2}\right)$ was monitored continuously by both upper and lower sensors. Raw optical data from the sensors were stored in a computer at 4-second intervals. After baseline $\mathrm{SrO}_{2}$ levels were recorded, segmental intercostal and lumbar arteries from T6 through L1 were sequentially occluded at approximately 10minute intervals. Each artery was initially occluded with a bulldog clamp; after approximately 10 minutes of clamping, $\mathrm{SrO}_{2}$ was recorded, and the artery was ligated with metallic clips and divided.

After all segmental arteries were ligated, $1 \mathrm{~mL}$ indocyanine green dye $(2.5 \mathrm{mg} / \mathrm{mL}$; Akorn, Inc, Buffalo Grove, Ill) was injected into the subarachnoid space through the spinal catheter. This dye absorbs near-infrared light in a band centered at $805 \mathrm{~nm}$. The catheter was flushed twice with $1 \mathrm{~mL}$ saline solution to distribute the dye evenly within the space surrounding the spinal cord. Optical density (the $\log$ of the ratio of measured intensity to incident intensity) at $810 \mathrm{~nm}$ was recorded with the oximeter to determine changes in light absorption. After ligation of the L1 segmental arteries in each of the 3 largest pigs, the animals were briefly awakened and examined for hind limb paralysis. After this examination, the animals were reanesthetized and humanely killed with intravenous potassium chloride.

\section{Histopathology}

The entire spinal column was removed from each of the 3 largest pigs and placed in formalin after the upper and lower segments monitored by the sensors were marked. Identification of the arteria radicularis magna (Adamkiewicz artery) was not attempted. The cords were sectioned, and representative portions of both regions were stained with either hematoxylin and eosin or luxol fast blue dye. A pathologist (F.J.C.) who was blind to the origin of each section (upper or lower cord) examined the sections and quantified ischemic change by counting the number of normal neurons and the number of ischemic neurons per section.

\section{Statistical Analysis}

The statistical analyses were performed with SPSS version 12.0 for Windows (SPSS Inc, Chicago, Ill). The following intraoperative variables were compared: mean upper- and lower-cord $\mathrm{SrO}_{2}$ values at baseline and after ligation of the segmental spinal arteries T6 through L1; absolute percentage $\mathrm{SrO}_{2}$ decline from baseline after each vessel was ligated; and mean heart rate, temperature, and mean arterial pressure. The upper and lower cords were compared in terms of the number of ischemic neurons and the ratio of ischemic to normal neurons. Continuous variables are reported as mean $\pm \mathrm{SD}$ and were analyzed with the Student $t$ test for betweengroup differences. We used analysis of variance for comparisons among three or more groups. The Bonferroni correction was used for multiple comparisons.

\section{Results \\ Clinical}

Mean physiologic parameters at baseline included heart rate of $99.0 \pm 3.6$ beats/min, mean arterial pressure of $55.3 \pm$ $4.3 \mathrm{~mm} \mathrm{Hg}$, and rectal temperature of $36.1^{\circ} \mathrm{C} \pm 1.9^{\circ} \mathrm{C}$. These parameters remained stable throughout the procedures. Baseline $\mathrm{SrO}_{2}$ values were similar in the upper 


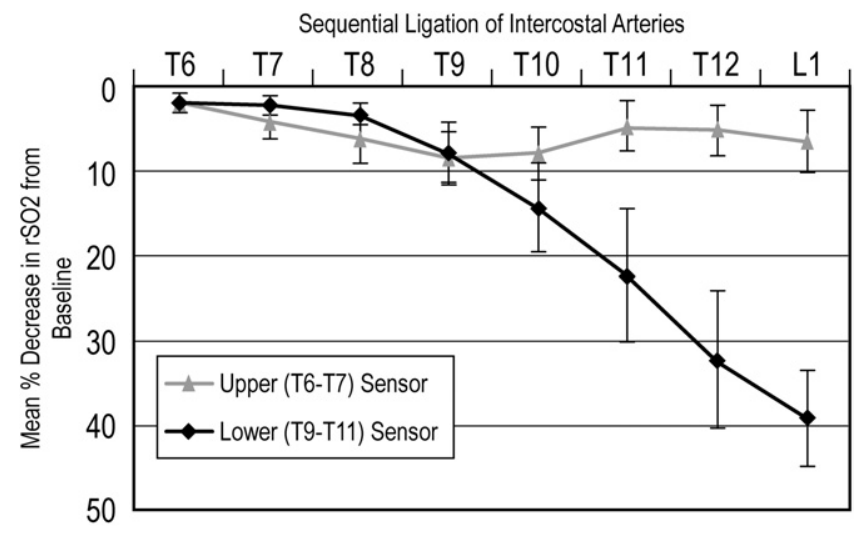

Figure 1. Graph showing percentage decline from baseline (mean $\pm \mathrm{SD}$ ) in $\mathrm{SrO}_{2}$ (rSO2) at T6-7 and T9-11 vertebral levels during sequential ligation of intercostal arteries. Once all vessels were ligated, decrease in $\mathrm{SrO}_{2}$ detected by lower sensor was significantly greater than that detected by upper sensor $(P=$ .026).

$(68.8 \% \pm 9.0 \%)$ and lower $(68.0 \% \pm 11.5 \%)$ cord segments $(P=.82)$. Upper-cord $\mathrm{SrO}_{2}$ remained stable throughout the procedure, whereas lower-cord $\mathrm{SrO}_{2}$ began to decrease after the T9 segmental artery was ligated. This decline continued after ligation of the T10 and T11 vessels and became statistically significant after ligation of T12 and L1. Most of the declines in $\mathrm{SrO}_{2}$ began within 1 minute of arterial ligation. After all segmental arteries were ligated, mean $\mathrm{SrO}_{2}$ levels were $64.8 \% \pm 9.3 \%$ in the upper cord and $41.3 \% \pm 10.1 \%$ in the lower cord $(P=.037)$; the percentage reduction in $\mathrm{SrO}_{2}$ from baseline was much larger in the lower cord $(39.0 \% \pm 11.5 \%)$ than in the upper cord $(6.3 \%$ $\pm 7.6 \%, P=.026$; Figure 1).

Subarachnoid injection of indocyanine green dye increased near-infrared light absorption at $810 \mathrm{~nm}$ (Figure 2) in all the pigs, indicating that a portion of the NIRS photons penetrated the tissues to the depth of the spinal cord. After injection of the dye, reductions in optical density (relative to baseline) for the 4 pigs were $12.3 \%, 20.7 \%, 33.1 \%$, and $21.2 \%$ (mean $21.8 \% \pm 8.6 \%$ ).

Lower spinal cord ischemia was also confirmed by physical examination. Three pigs were briefly awakened and examined after the operation, and paralysis of the hind limbs without involvement of the upper limbs was present in each.

\section{Histopathology}

The regional difference in the degree of ischemia was confirmed by microscopic examination of the lateral corticospinal tracts. Lower-cord sections exhibited more pronounced ischemic changes than did upper-cord sections, including increased vacuolization, retraction of neurons, and loss of nucleoli (Figure 3). Lower-cord sections also

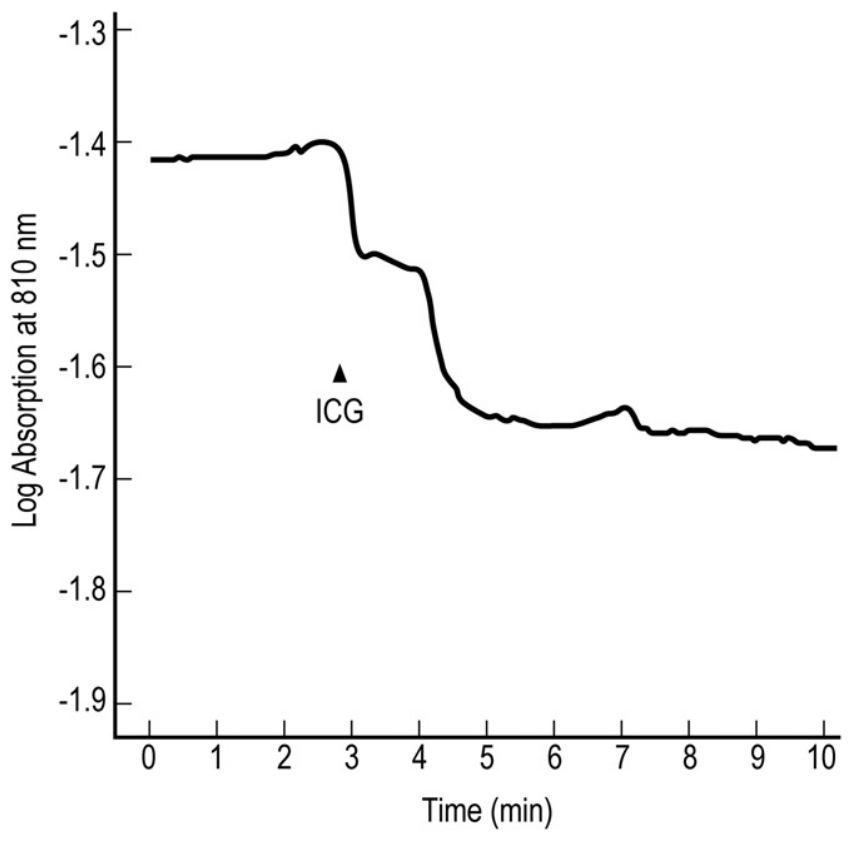

Figure 2. Representative graph showing increase in near-infrared light absorption at $810 \mathrm{~nm}$ after subarachnoid injection of indocyanine green dye (ICG).

had more ischemic neurons (mean $21.3 \pm 13.6$ per section) than did upper-cord sections (mean $8.8 \pm 9.4$ per section, $P$ $=.002$ ). These numbers corresponded to a significantly lower ratio of ischemic to normal neurons in the upper cord (0.17) than in the lower cord $(0.50, P=.005)$, indicating that the regional differences in spinal ischemia indicated by the NIRS monitor paralleled the regional histopathologic differences.

\section{Discussion}

Despite the use of numerous protective adjuncts during thoracoabdominal aortic surgery, spinal cord ischemic injury leading to paraplegia or paraparesis continues to be a significant problem. We recently reviewed contemporary reports of patients who underwent extensive thoracoabdominal aortic aneurysm (TAAA) repairs and found that neurologic deficits occurred in as many as $32 \%$ of patients. ${ }^{13}$ These neurologic deficits may contribute to mortality; in Svensson and colleagues' analysis ${ }^{14}$ of a series of TAAA repairs in 1509 patients, those who had paraplegia or paraparesis had a significantly lower 5-year survival (only $44 \%)$ than did patients without deficits $(62 \%, P<.0001)$ The risks of paraplegia and paraplegia-related death after descending thoracic aortic aneurysm and TAAA repair might be reduced if spinal cord perfusion and oxygenation could be monitored directly during surgery.

Attempts to monitor spinal cord perfusion indirectly during aortic aneurysm surgery began with the monitoring of 

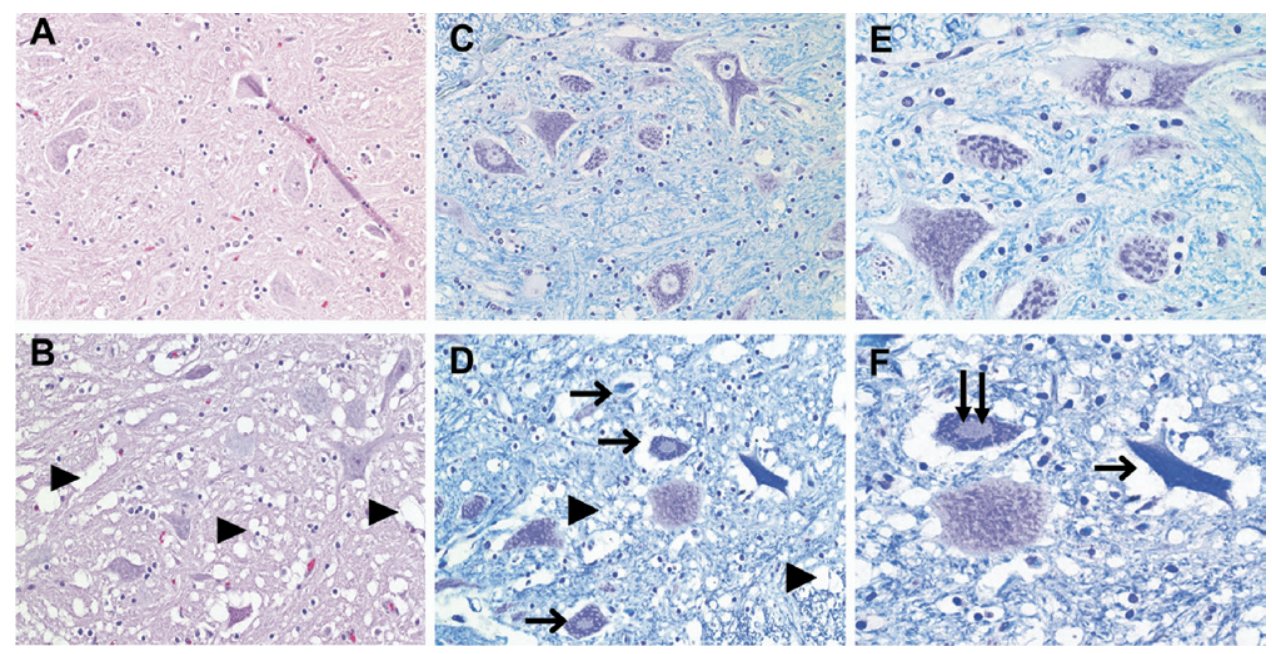

Figure 3. Representative histologic lateral corticospinal tract sections from upper (A, C, E) and lower (B, D, E) spinal cord. Compared with proximal sections, distal sections exhibited more pronounced ischemic changes, including increased vacuolization (arrowheads), retraction of neurons (arrows), and loss of nucleoli (double arrows). (Hematoxylin-eosin [A, B] and Luxol fast blue [C-F] staining; original magnifications $\times 20[A-D]$ and $\times 40$ $[E, F]$.

SSEPs, measurable electrical patterns that occur within the spinal cord when a peripheral sensory nerve (usually the posterior tibial nerve) is stimulated. ${ }^{15}$ Although SSEP monitoring showed promise in canine studies, ${ }^{16}$ a clinical trial by Crawford and associates ${ }^{2}$ showed that the measurement of SSEPs during aortic surgery did not reduce the incidence of postoperative neurologic deficits. ${ }^{17}$ The poor sensitivity and specificity of SSEP monitoring is partially attributable to the fact that the sensory and motor pathways of the spinal cord are anatomically separate and have different blood supplies. The amplitude of SSEPs only indicates the function of sensory tracts, which are located in the dorsal portion of the spinal cord and are not supplied by the anterior spinal artery, where blood flow is reduced during aortic clamping. As a result, SSEP monitoring provides only delayed information about spinal cord ischemia. ${ }^{18}$

In contrast, MEPs reflect the functional integrity of the motor pathways in the anterior (ventral) cord, especially the more vulnerable motor neurons in the anterior gray matter. Because the anterior cord is supplied by the anterior spinal artery, MEP monitoring is an anatomically and physiologically sound means of detecting spinal ischemia during aortic clamping. Jacobs and colleagues ${ }^{1,5-7}$ have used MEP monitoring as part of their spinal cord protection strategy and have achieved excellent results. In a pilot study involving 52 consecutive patients with Crawford extent I or II TAAAs, Jacobs and colleagues ${ }^{1}$ recorded MEPs in all patients and reported that spinal cord ischemia was detected as early as 2 minutes after intercostal artery ligation. During distal aortic perfusion, 14 patients showed a rapid decrease in MEP amplitude to less than $25 \%$ of baseline, indicating spinal cord ischemia; this was corrected by increasing distal aortic pressure. Additionally, in 33 patients, aggressive reattachment of intercostal arteries returned MEP amplitudes to baseline levels, and no early or late paraplegia occurred. Jacobs and Mess $^{5}$ recently reported preventing neurologic deficits in $98 \%$ of patients undergoing TAAA repair by using MEP monitoring.

MEP monitoring is not, however, without limitations. ${ }^{19,20}$ For example, the neuromuscular blocking agents that are part of the usual anesthetic regimen interfere with MEP monitoring. For this reason, MEP monitoring requires alterations in standard anesthetic management to prevent complete neuromuscular blockage. Also, MEP monitoring depends on signal averaging across a span of seconds, which limits its ability to detect vascular compromise before neurons have been irreversibly injured. Additional limitations of this technique include the need for monitoring by a neurophysiologist during the operation and its inability to be used in conscious postoperative patients. For these reasons, although MEP monitoring has been shown to reduce the risk of paraplegia, the technique is not widely used.

Other methods of monitoring spinal cord ischemia currently being studied include intrathecal monitoring of cerebrospinal fluid oxygen tension ${ }^{21,22}$ and transesophageal NIRS monitoring of spinal cord $\mathrm{Sro}_{2} \cdot{ }^{23}$ An ideal spinal cord monitoring method would (1) be noninvasive, (2) be simple enough to use that no additional personnel are required, (3) be highly sensitive and specific to changes in the anterior spinal cord, (4) allow standard anesthesia delivery, (5) ex- 
hibit no delay in ischemia detection, and (6) be usable in conscious postoperative patients. Transcutaneous NIRS has the potential to satisfy these criteria.

Our pilot study was designed to assess the potential usefulness of transcutaneous NIRS as a noninvasive monitor that provides continuous, real-time information about spinal cord oxygenation. NIRS uses transcutaneous sensors to measure the focal oxyhemoglobin fraction in underlying tissue. Currently, this technique is used to monitor cerebral oxygenation during a wide variety of cardiovascular operations. ${ }^{4,9,10,12,24}$ In addition to being entirely noninvasive, the NIRS monitor is simple to use, requires no additional technical personnel, and does not require modifications to anesthetic management. In our experiment, we showed that transcutaneous NIRS can detect intraoperative spinal cord ischemia in a porcine model.

An initial concern was that the sensors would detect oxygenation levels in the surrounding tissues, such as muscle and subcutaneous tissue, but not in the underlying spinal cord. Given the anatomy of the blood supply shared between the spinal cord and these surrounding tissues, however, NIRS data on regional oxygenation may adequately reflect spinal cord perfusion, albeit indirectly. To address this issue specifically, we injected indocyanine green dye into the subarachnoid space and found an immediate change in light absorption (Figure 2), suggesting that at least some of the photons were reaching the spinal cord. Additionally, Macnab and coworkers ${ }^{25}$ found that, in a porcine model of spinal cord hypoxia-ischemia, NIRS detected ischemic changes in the spinal cord whether the sensors were placed directly on the spinal cord, the spinal lamina, or the spinous processes. Further experiments correlating direct measurements of spinal oxygenation with transcutaneous NIRS readings would help clarify this issue.

Real-time information about spinal cord perfusion during TAAA repair would allow the surgical team to intervene when ischemia occurs. Intervention strategies used during $\mathrm{SrO}_{2}$ monitoring could be based on those outlined in Jacobs and colleagues' report ${ }^{1}$ regarding MEP monitoring during TAAA surgery. For example, when ischemia is detected, the mean arterial pressure could be immediately increased. Distal aortic flow and pressure could also be increased when left heart bypass is being used. Additionally, temporary occlusion catheters could be placed in segmental arteries with significant back-bleeding, thereby reducing steal from the anterior spinal artery. Finally, decline in $\mathrm{SrO}_{2}$ could prompt the reattachment of specific segmental arteries within the isolated aortic segment, and aortic endarterectomy could be performed when segmental arteries are not readily apparent.

Because of its potential value in guiding these types of interventions, NIRS monitoring of spinal cord oxygenation during thoracic aortic surgery is worthy of clinical investi- gation. Expanding the application of NIRS to postoperative spinal cord monitoring as a means of preventing delayedonset paraplegia also merits study.

We gratefully acknowledge Paul Holman, MD, Jean-Paul Wolinsky, MD, Jamie Junkerman, and Gobind Anand for intraoperative assistance; and the staff at the Cullen Cardiovascular Research Laboratory of the Texas Heart Institute-especially Kathleen McKay, Blake Deady, and Amy Porter-for excellent anesthetic management. Stephen N. Palmer, PhD, ELS, provided editorial assistance, and Scott Weldon, MA, provided assistance with illustrations.

\section{References}

1. Jacobs MJ, Meylaerts SA, de Haan P, de Mol BA, Kalkman CJ. Strategies to prevent neurologic deficit based on motor-evoked potentials in type I and II thoracoabdominal aortic aneurysm repair. J Vasc Surg. 1999;29:48-57.

2. Crawford ES, Mizrahi EM, Hess KR, Coselli JS, Safi HJ, Patel VM. The impact of distal aortic perfusion and somatosensory evoked potential monitoring on prevention of paraplegia after aortic aneurysm operation. J Thorac Cardiovasc Surg. 1988;95:357-67.

3. Schepens MA, Boezeman EH, Hamerlijnck RP, ter Beek H, Vermeulen FE. Somatosensory evoked potentials during exclusion and reperfusion of critical aortic segments in thoracoabdominal aortic aneurysm surgery. J Card Surg. 1994;9:692-702.

4. Reuter DG, Tacker WA Jr, Badylak SF, Voorhees WD 3rd, Konrad PE. Correlation of motor-evoked potential response to ischemic spinal cord damage. J Thorac Cardiovasc Surg. 1992;104:262-72.

5. Jacobs MJ, Mess WH. The role of evoked potential monitoring in operative management of type I and type II thoracoabdominal aortic aneurysms. Semin Thorac Cardiovasc Surg. 2003;15:353-64.

6. Jacobs MJ, Elenbaas TW, Schurink GW, Mess WH, Mochtar B. Assessment of spinal cord integrity during thoracoabdominal aortic aneurysm repair. Ann Thorac Surg. 2002;74:S1864-6.

7. Jacobs MJ, Meylaerts SA, de Haan P, de Mol BA, Kalkman CJ. Assessment of spinal cord ischemia by means of evoked potential monitoring during thoracoabdominal aortic surgery. Semin Vasc Surg. 2000;13:299-307.

8. Edmonds HL Jr, Rodriguez RA, Audenaert SM, Austin EH 3rd, Pollock SB Jr, Ganzel BL. The role of neuromonitoring in cardiovascular surgery. J Cardiothorac Vasc Anesth. 1996;10:15-23.

9. Cho H, Nemoto EM, Yonas H, Balzer J, Sclabassi RJ. Cerebral monitoring by means of oximetry and somatosensory evoked potentials during carotid endarterectomy. J Neurosurg. 1998;89:533-8.

10. Daubeney PE, Smith DC, Pilkington SN, Lamb RK, Monro JL, Tsang VT, et al. Cerebral oxygenation during paediatric cardiac surgery: identification of vulnerable periods using near infrared spectroscopy. Eur J Cardiothorac Surg. 1998;13:370-7.

11. Deeb GM, Jenkins E, Bolling SF, Brunsting LA, Williams DM, Quint LE, et al. Retrograde cerebral perfusion during hypothermic circulatory arrest reduces neurologic morbidity. J Thorac Cardiovasc Surg. 1995;109:259-68.

12. Murkin JM. Perioperative detection of brain oxygenation and clinical outcomes in cardiac surgery. Semin Cardiothorac Vasc Anesth. 2004; 8:13-4.

13. Coselli JS, LeMaire SA, Conklin LD, Köksoy C, Schmittling ZC. Morbidity and mortality after extent II thoracoabdominal aortic aneurysm repair. Ann Thorac Surg. 2002;73:1107-15.

14. Svensson LG, Crawford ES, Hess KR, Coselli JS, Safi HJ. Experience with 1509 patients undergoing thoracoabdominal aortic operations. $J$ Vasc Surg. 1993;17:357-68.

15. de Mol BA, Boezeman EH, Hamerlijnck RP, de Geest R. Experimental and clinical use of somatosensory evoked potentials in surgery of aneurysms of the descending thoracic aorta. Thorac Cardiovasc Surg. 1990;38:146-50.

16. Grabitz K, Freye E, Sandmann W. Somatosensory evoked potential, a prognostic tool for the recovery of motor function following 
malperfusion of the spinal cord: studies in dogs. J Clin Monit. 1993;9:191-5.

17. Mizrahi EM, Crawford ES. Somatosensory evoked potentials during reversible spinal cord ischemia in man. Electroencephalogr Clin Neurophysiol. 1984;58:120-6.

18. Meylaerts SA, Jacobs MJ, van Iterson V, De Haan P, Kalkman CJ. Comparison of transcranial motor evoked potentials and somatosensory evoked potentials during thoracoabdominal aortic aneurysm repair. Ann Surg. 1999;230:742-9.

19. van Dongen EP, Schepens MA, Morshuis WJ, ter Beek HT, Aarts LP, de Boer A, et al. Thoracic and thoracoabdominal aortic aneurysm repair: use of evoked potential monitoring in 118 patients. J Vasc Surg. 2001;34:1035-40.

20. Guerit JM, Dion RA. State-of-the-art of neuromonitoring for prevention of immediate and delayed paraplegia in thoracic and thoracoabdominal aorta surgery. Ann Thorac Surg. 2002;74:S1867-9; discussion S1892-8.
21. Lips J, de Haan P, Bouma GJ, Holman R, van Dongen E, Kalkman CJ. Continuous monitoring of cerebrospinal fluid oxygen tension in relation to motor evoked potentials during spinal cord ischemia in pigs. Anesthesiology. 2005;102:340-5.

22. Christiansson L, Karacagil S, Thelin S, Hellberg A, Tyden H, Wiklund $\mathrm{L}$, et al. Continuous monitoring of intrathecal $\mathrm{pO}_{2}, \mathrm{pCO}_{2}$ and $\mathrm{pH}$ during surgical replacement of type II thoracoabdominal aortic aneurysm. Eur J Vasc Endovasc Surg. 1998;15:78-81.

23. Kunihara T, Shiiya N, Matsui Y, Yasuda K. Preliminary report of transesophageal monitoring of spinal cord ischemia using nearinfrared spectrophotometry. J Cardiovasc Surg (Torino). 2004;45: 95-6.

24. Murkin JM. Etiology and incidence of brain dysfunction after cardiac surgery. J Cardiothorac Vasc Anesth. 1999;13:12-7.

25. Macnab AJ, Gagnon RE, Gagnon FA. Near infrared spectroscopy for intraoperative monitoring of the spinal cord. Spine. 2002;27: $17-20$.

\section{Online-www.aats.org}

Now you can get The Journal of Thoracic and Cardiovascular Surgery online. The Journal online brings you faster delivery time, easy searching of current and back issues, links to PubMed, AATS, WTSA, and other important sites, and more. Visit the Journal online today.

\section{Receive tables of contents by e-mail}

To receive the tables of contents by e-mail, sign up through our Web site at http://journals.elsevierhealth.com/periodicals/ymtc

Choose E-mail Notification

Simply type your e-mail address in the box and click the Subscribe button. You will receive an e-mail to confirm that you have been added to the mailing list.

Note that TOC e-mails will be sent out when a new issue is posted to the Web site. 